\title{
THE DOCUMENTATION AND REINTEGRATION OF A LOST PAST
}

\author{
C. Balletti, N. Brussa, C. Gottardi, F. Guerra
}

Università Iuav di Venezia - (balletti, guerra2@iuav.it)

Commission V

KEY WORDS: Cultural Heritage, Laser scanning, Image, Three-dimensional, Representation

\begin{abstract}
:
The paper describes how new digital methodologies can be used within the field of Cultural Heritage, not only with the aim of documenting the actual state of an architecture but to review the past transformations it has undergone, conserving and representing these histories as well.

Over the last few years, the methodologies of acquisition and integrated representation for 3D patrimony documentation have developed and consolidated considerably: the possibilities of the digital realm can augment the understanding and the valorisation of a monument.

The specific case offered in the present paper, the Scuola Vecchia della Misericordia in Venice, is a significant example. It suggests not only the theme of the "no longer existing" regarding its façade, which has undergone evident modifications, but also the recontextualization of a number of decorative elements, such as the bas-reliefs which once marked the entrance and are today conserved in the Victoria and Albert Museum, London.

The described experience shows how integrated methodology, from high resolution laser scanning and photogrammetric survey to $3 \mathrm{~d}$ modelling, can develop a reliably virtual diachronical reconstruction from different sources of an historical building. Geomatic tools combined with computer graphics provide a better understanding of building history through the use historical documents, playing a paramount role in preserving and valorizing the cultural and environmental heritage.
\end{abstract}

\section{INTRODUCTION}

The affirmation of digital technology within the field of Cultural Heritage has brought forth the awareness that $3 \mathrm{D}$ surveying and modelling can play a very important role in the understanding, restoration and valorisation of Cultural Heritage. This consideration is particularly evident when it's applied to historic architecture.

Today technologies and methodologies in this field of application allow to record the position, size and shape, as well as generate very accurate and realistic 3D models in terms both of geometry and of textures, that are required in any project related to the conservation of cultural heritage, forming an important element of the documentation and analysis process (English Heritage, 2011).

There are many contributions that highlight not only the procedures for the acquisition of the state of conservation by using $3 \mathrm{~d}$ integrated survey methods, but also provide some important requirements for the documentation and preservation to provide a basis for scientific monitoring and planning of restoration work or final visualization of our heritage (Guidi et al., 2004; Cignoni et al., 2008; Remondino, 2010; Murphy et al., 2011; Brunetaud, X. et al., 2012;). Digital photogrammetry and laser scanning, that are suddenly called reality-based techniques (Remondino, 2010; Battiato et al., 2011) employ hardware and software to survey the reality as it is, documenting the actual or as-built situation of a site and reconstructing it from real data.

This paper describes the study undertaken upon the diverse geometrical-decorative configurations, which, one after another, have successively adorned the façade of the Scuola Vecchia della Misericordia between the Fourteenth and Sixteenth centuries. The construction, dating from the early 1300's, reveals gaps that are easily identified from the evident material traces; the façade as well presents some incongruities in the mounting of the ashlar masonry in the crowning pediment. This detail suggests past transformations, without, however, indicating how the Scuola's appearance originally might have been.

The current study proposes a process of "virtual reintegration" where 3D surveys, initially used to support the stratigraphic analysis providing interpretative hypothesis, now become the fundamental instrument in furnishing virtual reconstructions coherent with the historic, geometric and material documentation.

\section{HISTORY AND ICONOGRAPHY}

Documentation of the construction is scarce and the first mention of it is found in the Venice guide by Francesco Sansovino, Venetia citta nobilissima et singolare from the year 1581 (Sansovino, 1581; Wolters, 1976; Nepi Scirè, 1978). Then there is the research conducted by Pietro Paoletti, published in L'architettura e la scultura del rinascimento a Venezia at the end of the Nineteenth century and finally in the Scuola's registries (Paoletti di Osvaldo P., 1893). Paoletti in particular indicates in minute detail the supplies of materials, the respective moneys paid and testamentary donations. All the same he fails to give any mention or make any reference to the formal-architectural types such as modifications or substitutions executed at the time of construction.

What is known regarding the succession of portals is that the first one produced goes back to the first years of the 1300's, within the context of the construction of the edifice. Later, on the occasion of façade's remodelling during the first half of the 1400 's, this was removed and transferred to the entrance of the Corte Nova, in the neighbouring fondamenta about 500 meters from the original site. In the same period, the registries note the commission, probably given to Bartolomeo Bon, a member of the confraternity, to produce a panelo grande, a large panel that would have substituted its predecessor. On the façade today 
there remains only the two abutments and the architrave. The bas-relief portraying the Madonna the members of the brotherhood at Her feet constituted together with another, larger structure the upper portion of the decorated portal. It is conserved in the Victoria and Albert Museum, London. The rest of the stone carving work has vanished.

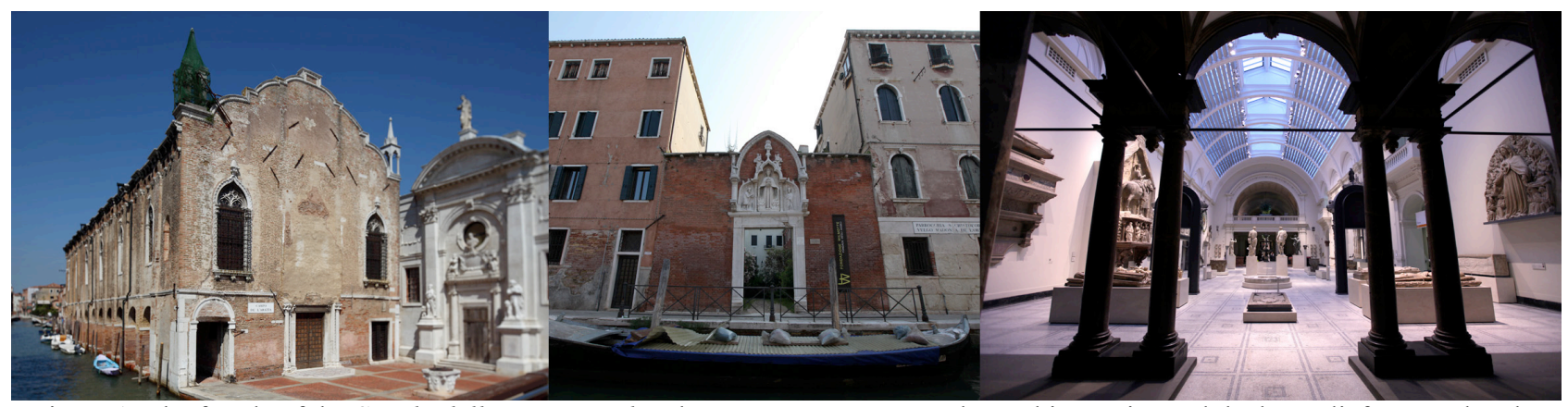

Figure 1: The façade of the Scuola della Misericordia, the XIV century removed portal in Venice and the bas-relief exposed at the
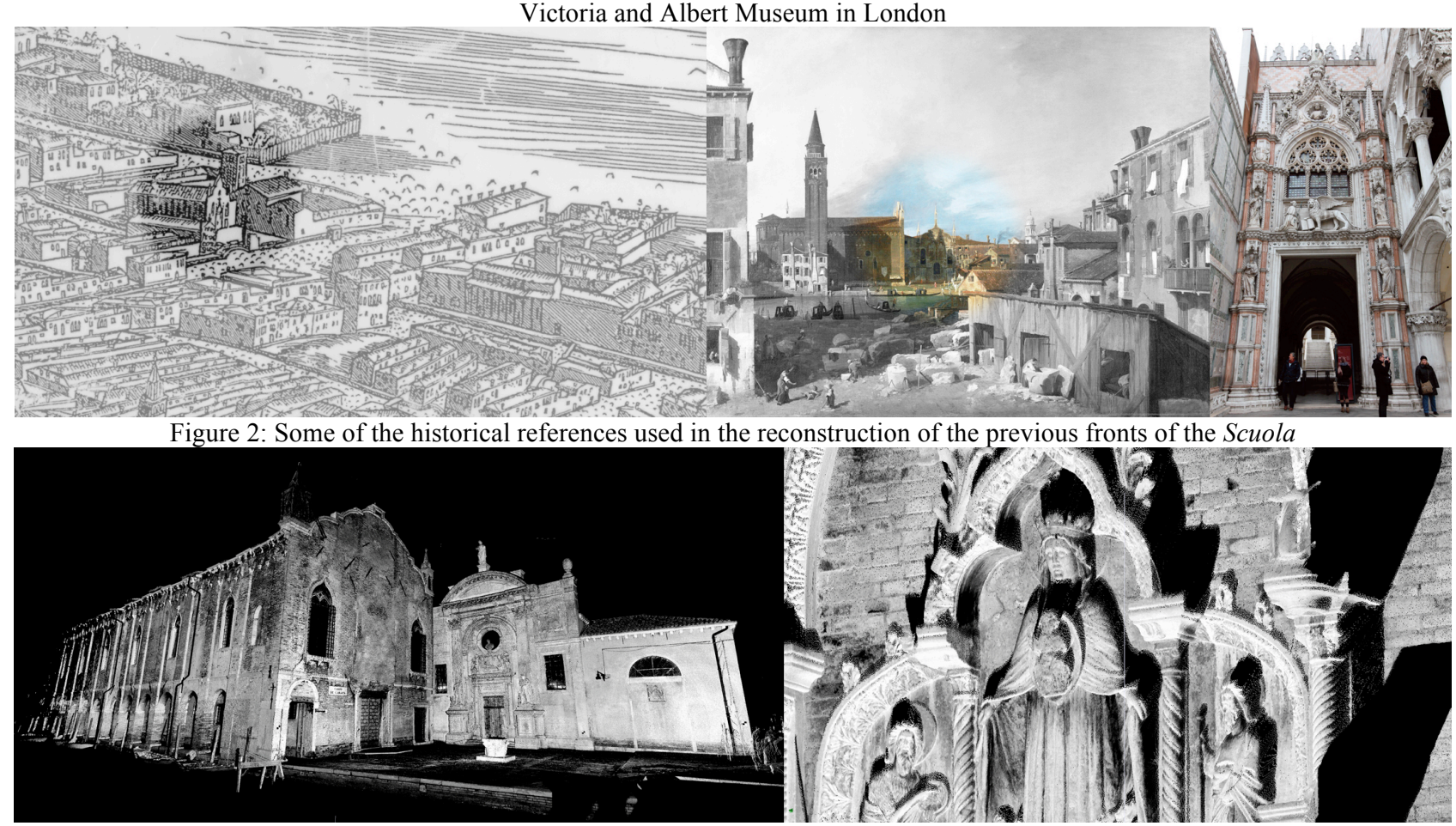

Figure 3: The point clouds of the façade and a detail of the removed portal in Venice

The only iconographic representation from which we may glean some accurate information regarding the configuration of the Scuola Vecchia's façade is provided by the famous illustration by de' Barbari from 1500. The façade at that time is differentiated from the present one by its mixtilinear pediment and for the presence of a central, round window opening, later closed up. Furthermore one may notice in the image where, in the neighbouring insula, can be seen the construction site of the future Scuola Grande by Jacopo Sansovino.

A second iconographic document, not directly relevant to the Scuola, but surely useful for a formal-stylistic comparison, is the painting of the stone carver's courtyard by Canaletto circa 1727. In this, one may see the façade of the Scuola della Carità (today the Accademia).

The comparison with constructions from the same period, within the same area or even produced by the same stonemasons often allows one to elaborate efficient reconstructive hypothesis regarding their historical analysis on the basis of typological and formal analogies (Figure 2). In the case of the Scuola della
Misericordia, the following were considered for the affinities of their architectural configurations: the churches of Santa Maria Gloriosa dei Frari (1330-1440), Sant'Andrea della Zirada (1350-1470), San Giovanni in Bragora (1470-1505), Madonna dell'Orto (1480) and the famous Porta della Carta (1438-1442).

\section{Reality based survey: laser scanning point clouds}

As is well known, there is a variety of techniques available to generate three-dimensional survey information. These techniques can be characterised mainly by the scale at which they might be used which is related to the size of the object to be measured, or to the complexity of the object (English Heritage, 2011).

Digital photogrammetry and terrestrial laser scanning could be used to provide a greater number of measurements for similar object sizes, and therefore, are suitable to be integrated for more complex objects acquisition.

The archival and bibliographic research has demonstrated a scarce documentation of the construction and its transformations, even in recent periods. This made it necessary 
to execute a survey of the Scuola's current state, the $14^{\text {th }}$ century portal recomposed nearby and the bas-relief conserved in London. The acquisition of metric data occurred during two survey campaigns, which saw the integration of different methodologies above all because of the locations of operation: laser scanning for the Venice campaign and digital photogrammetry for the acquisitions in London.

The edifice as seen today was surveyed with a range image laser Focus3D by Faro. The instrument, well known in the field of architectural surveying (Balletti c. et al, 2013, Giannattasio et al., 2013), has shown itself to be particularly suited to the acquisition of data both internally and externally. These applications are related not only to documentation but also to the sectors of restoration and industry.

The apparatus is extremely rapid and its dimensions (24 centimetres $\times 20 \mathrm{~cm} \times 1 \mathrm{~cm}$ ) and weight (5 kilograms) are limited (www.faro.com). This laser scanner, endowed with a wlan (wifi) which allows one to manage the scanning at a distance removed from the work area, is characterized by a range between 0.6 and $120 \mathrm{~m}$ and an accuracy of $\pm 2 \mathrm{~mm}$ for distances ranging from 10 to 25 meters. The instrument provided the precision necessary for the surveying of the Scuola on a architectural scale: the scanner 's measurements uncertainty is smaller than the required scale resolution 1:50 (i.e. $\pm 10 \mathrm{~mm}$ ). Its ample visual field (a vertical of $305^{\circ}$ and a horizontal of $360^{\circ}$ ) renders it particularly suited to constricted urban areas such as that of Venice. The velocity of the scans (up to 976.000 points $/ \mathrm{sec})$ and that selected for this project $(244 \mathrm{kpt} / \mathrm{sec})$ allowed for a reduced scanning time (about 7-8 minutes per scan). Each acquired point is characterized by an RGB value thanks to the integrated digital photo camera with a 70 megapixel resolution.

Four scans were executed for the building's façade for a total of 156.271.321 points with a density of one point every three millimetres from a distance of ten meters. For the $14^{\text {th }}$ century portal four scans were executed for a total of 44.234 .861 points (Figure 3).

The acquisition of the scans using the Focus3D was accompanied by topographical support for a greater control of the cloud alignments in the same reference coordinates system; a small topographical network was made from whose vertices were detected control points. A Leica TCR 1103 total station theodolite (TST) was used for point acquisition. The estimated points' accuracy was $\pm 2 \mathrm{~mm}$.

The scans of the main façade and of the XIV century removed portal were acquired with a step angle of $0.035^{\circ}$ in order to guarantee the acquisition of a point every $6 \mathrm{~mm}$ from a distance of 10 meters.

The elaboration phase of the data followed that of their acquisition: with the use of specialized software (FARO Scene, Pointools) the 8 scans were aligned through a methodology known as "target georeferencing" which includes the use of topographical data acquired by the TST. In this manner a single cloud composed of 450.000 .000 points was obtained. Considering the average distance between the instrument and the surface to be surveyed and the number of scans made the average precision obtained after the alignment was $4 \mathrm{~mm}$, so the final data can be considered adequate to a scale of 1:50.

The aligned point clouds were then uploaded into Geomagic for the realization of the mesh and all the editing operations needed to obtain the final model. We used the Studio version of the software, which contains many useful mesh-altering tools including: hole fixing, mesh slicing and edge repairs. Any gaps or holes in the mesh were filled or corrected to ensure that the texture had a complete surface on which to project.

\section{Image based survey}

On the other hand, a second survey campaign was conducted at the Victoria and Albert Museum in London, where it is now conserved the XV century bas-relief depicting the Madonna.

Today the bas-relief is completely out of context: it is exhibited in the London Museum without any reference to its original location over the entrance of the Scuola from the fifteenth to the seventeenth century. To avoid disturbing the activities carried out within the museum and also for greater simplicity in the transfer, it was decided to replace the laser scanning acquisition with a digital camera and then with automated digital photogrammetry, particularly using the Structure From Motion (SFM) and Dense Multi- View 3D Reconstruction (DMVR) algorithms. These algorithms simultaneously estimate the parameters of internal and external orientation and the coordinates of the object.

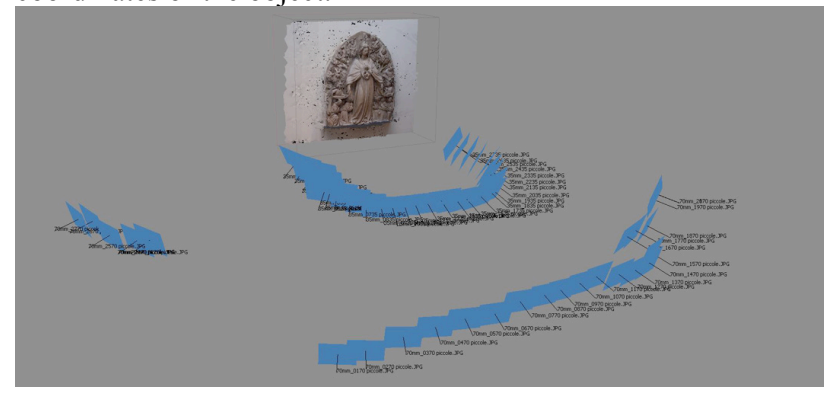

Figure 4: a screenshot of the Photoscan project
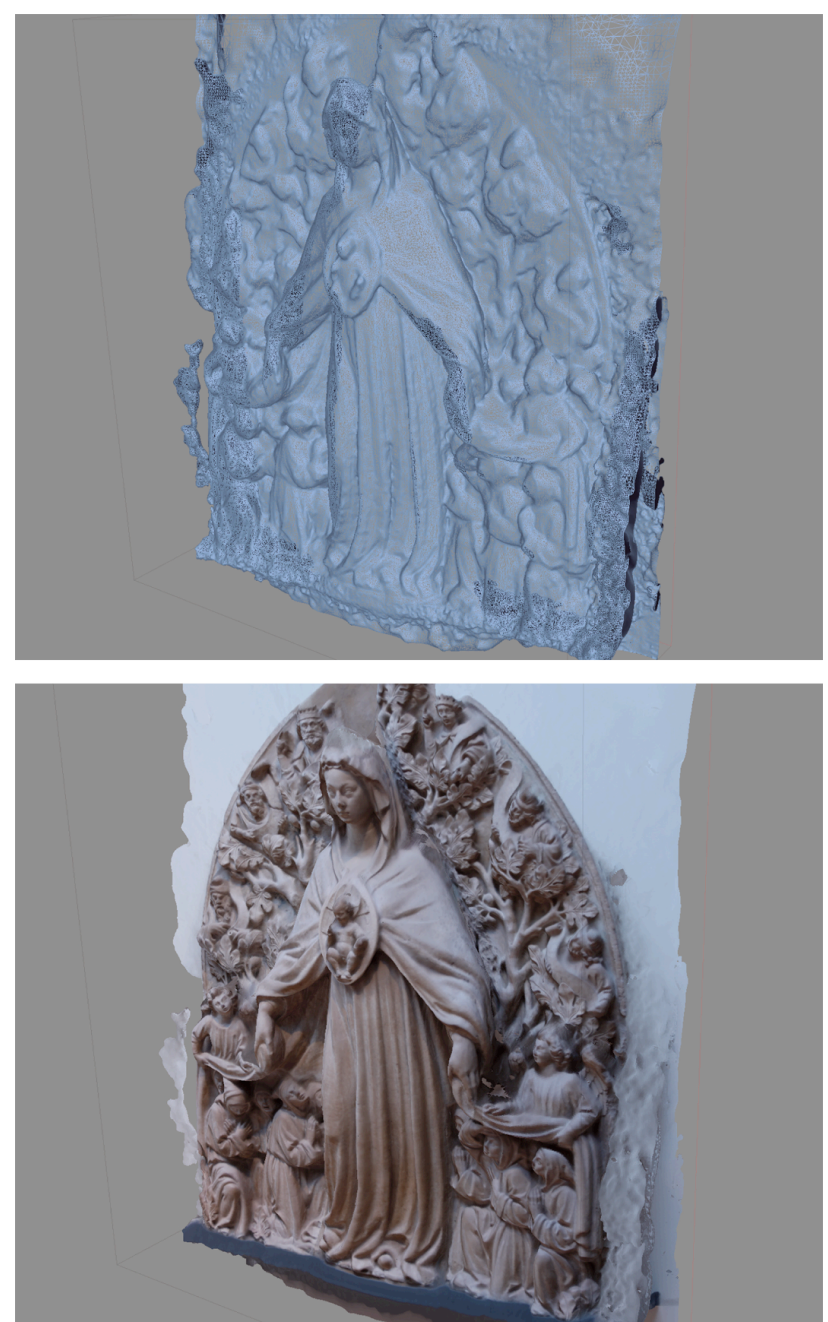

Figure 5-6: a detail of the output mesh of the London stonework 
To optimize the reconstruction of the geometry of the object, a self-calibration procedure of the camera is needed by means of a least squares solving system (bundle adjustment), in which additional information about the block (control points, distances, notes, etc.) can be load.

Today, some interesting tools for close range applications are developed in the areas of computer graphics, computer science and automation, to support 3D acquisition in a short time and with low costs (Remondino et al., 2006, Koutsoudis, et al., 2014, Lo Brutto, 2012).

A Canon 5D Mark II camera with a fixed $35 \mathrm{~mm}$ and $70 \mathrm{~mm}$ lens was used for the photogrammetric survey of a double set of images. The full-frame 21 megapixel sensor provides high resolution images. Approximately 60 photographs have been acquired and oriented to model the bas-relief. The scheme of photographs' acquisition is shown in Figure 4: the first is parallel to the wall, at a distance of $6 \mathrm{~m}$, and the second in a semicircle, closer (about $3 \mathrm{~m}$ ) to the relief to obtain a greater detail (1pixel corresponds to $1 \mathrm{~mm}$ on the object). To not interfere with museum activities, it has not been possible to survey topographically some control points, but only some linear distances were acquired for the scaling.

The captured frames were processed with the software Photoscan by Agisoft, one of the major commercial SFMDMVR representatives currently available. The SFM method uses a number of unordered images that depict an object from arbitrary viewpoints and attempts to recover camera parameters and a sparse point cloud that represents the 3D geometry of a scene. Camera pose and scene geometry are reconstructed simultaneously through the automatic identification of matching features in multiple images. These features are tracked from image to image, enabling initial estimates of camera positions and object coordinates, which are then refined iteratively using non-linear least-squares minimisation (Westoby et al., 2012)

The procedure of photographs (http://www.agisoft.ru/) processing and $3 \mathrm{D}$ model construction of the bas-relief can be describe in four main stage: the first one is the camera alignment: the SW searches for common points on photographs and matches them, as well as it finds the position of the camera for each picture and refines camera calibration parameters. As a result a sparse point cloud and a set of camera positions are formed (Figure 4). Data were divided into 2 chunks (related to 35 and $70 \mathrm{~mm}$ lenses), later merged.

The next stage is building dense point cloud based on the previous estimated camera positions and pictures themselves. Processing times were quite long ( about 48 hours for chunk) just to get a very detailed model. The $3 \mathrm{D}$ polygonal mesh, representing the object surface based on the dense point cloud, is obtained (Figure 5-6).

It is to be underlined that it is possible to set the accuracy of every phase of the whole pipeline, from the images orientation to the $3 \mathrm{D}$ reconstruction. Moreover some editing commands to modify or to improve the obtained 3D model are available, such as mesh decimation, removal of detached triangles, closing of holes, etc. even if the final model of the Madonna was imported in Geomagic Studio to better perform a complete 3D model composed of 100 million triangles.

Considering the density of the final point cloud (that is lower than the $6 \mathrm{~mm}$ of single scan), the obtained level of detail was considered more than sufficient for this work of documentation. The produced model was scaled on the base of some linear distances acquired in loco and subsequently inserted in the model of the facade obtained with the laser scanning survey. In this phase it is applied a best fitting transformation (on the basis of material tracks still legible on the masonry, comparing it to the size of the visible frame above the entrance, and also considering the proportions of the composition deduced from the stylistic comparison with other similar contemporary portals) to obtain a greater correspondence and coherence between the bas-relief and the venetian building.

In this operation it is difficult to speak of precision when merging the sculptural element into the entire facade, with the meaning commonly adopted in surveying, but it is quite correct to define the likelihood of the operation from the point of view of historical documents.

\section{Analysis of the current construction and the virtual reconstruction}

Upon conclusion of the survey campaign for data acquisition an orthophoto was the first item produced. It is an orthophoto of the façade at a nominal scale of 1:20 in support of the stratigraphic analysis for individuating and localizing the presence of different typologies of masonry.

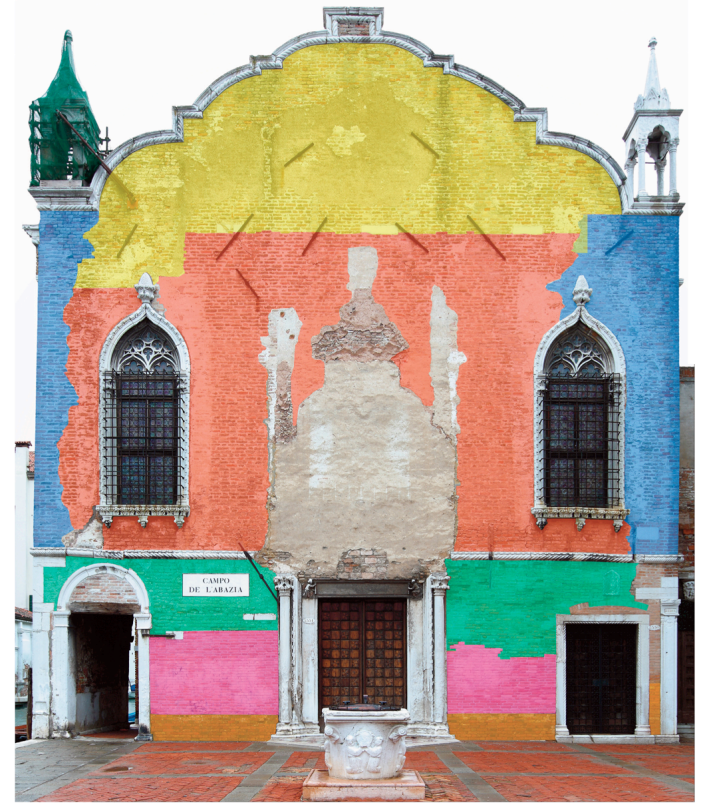

Figure 7: a rectified image with the detected masonry differences

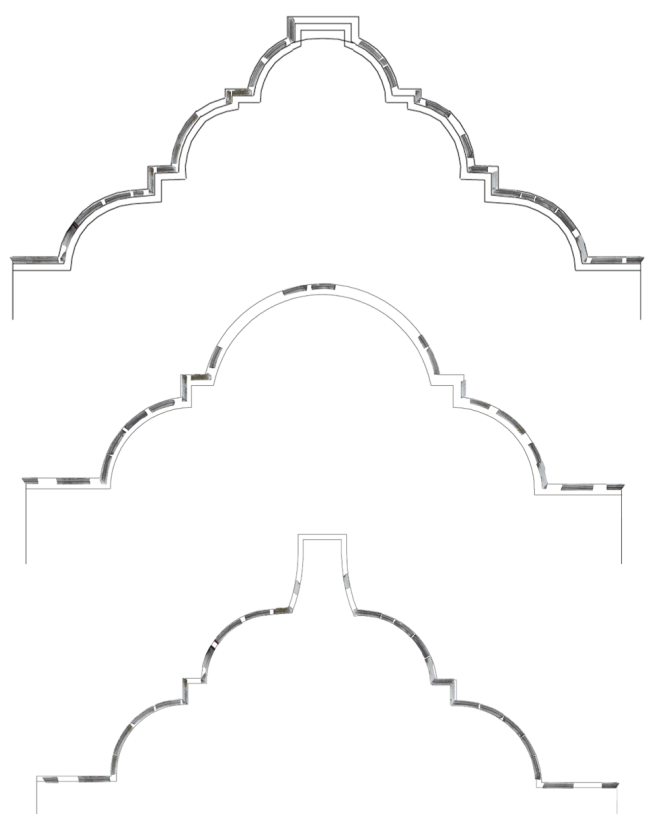

Figure 8: upper frame hypothesis 
The collected data (locations of deterioration, and architectural and historical archives) must be referenced in a single documentation platform to establish a detailed diagnosis of the state of degradation of the monument (Figure 7).

The stratigraphic reading confirms the hypothesis of substantial modifications to the upper portion of the façade. This hypothesis is further supported by the geometrical analysis of ashlar masonry in the crowning pediment.

Portions of original masonry that has remained unchanged are evident in the central part of the façade. These are analogous to the composition of that along the side of the canal, which is also believed to be the oldest section of the construction. Other portions feature irregular compositions characterized by the presence of brick fragments and irregularly positioned layers due to restructuring and re-adaptation. The masonry in the upper part of the façade as well, is particularly indicative by the line of the upper fiube - metal tie beams, found up to the crowning pediment, which reveal substitutions. Such substitutions demonstrate the execution of modifications throughout the upper part of the façade and, consequently, of the crowning pediment.

Near the corners and throughout the base area to be noted numerous small interventions and repairs due to the decay of materials more exposed to the decay of the structure.

An additional observation may be made within the proximity of the window openings, confirming their depth with respect to the original masonry that confines them. The abutments are in fact inserted in the breaches.

A number of scholars, including Wolfgang Wolters (Wolters, 1976) support the thesis attributing the authorship of these, through their stylistic comparison, to the same author of the portal. Thanks to the ample curvature of the ashlar stonework, in the crowning stone pediment, as mentioned previously, there is to be observed by way of a hypothetical and virtual dismantling of the single ashlar blocks of which it is constituted and, successively by an operation of anastylosis, the potential configurations which may be arrived at by "playing" with them. It is important to emphasize that this first operation was undertaken without observing the historical sources in order to maintain the greatest liberty of hypothesis, but rather working on analogies with other factories.

Once the three reconfigurations had been produced, they were then compared with the historic models present in the city in order to arrive at a hypothesis for a façade as close to authentic as possible (Figure 8).

Regarding on the other hand the reconstructive hypothesis of the "structure" in which the London bas-relief was inserted, the research extended to stylistic comparisons beyond the confines of Venice. The reason being that it is difficult to find that which, in terms of Venetian portals from the first half of the $15^{\text {th }}$ century, we would usually name a "topos" along with its variations, where it would be more opportune in such a context to speak of "individuals".

Of such works present in Venice that could serve to similarities in the reconstruction, those studied include the Porta della Carta of the Doge's Palace by Bartolomeo Bon and produced between 1439 and 1442; the portal of the church of Madonna dell'Orto in Canareggio produced around 1480 again by Bon. Finally, for completion's sake, the portals of the churches of Santo Stefano (1430) and of Santa Maria Gloriosa dei Frari (1330-1440).

Outside of Venetian territory, however, the portals of Sant'Agostino at Pesaro (1398-1413) and of Sant'Agostino at Ancona (1460), which, together with the Porta della Carta, could provide a coherent explanatory example.

In a society in which visual communication now has a fundamental role in disseminating information, the 3D model appropriately adjusted through today's technological possibilities - can provide a message that is easily perceived and extremely incisive in communicating information about our Cultural Heritage.

In regards to a specific building, a 3D model can be generated with two different criteria. On the one hand, the monument's current condition can be faithfully represented by using advanced digital survey techniques and then modelling and representation processes based on true geometrical data, as was done, and previously described, in the case of the Ancient School of Misericordia. On the other hand, 3D digital reconstructions can be conceived on the basis of historical information and drawings, following a research approach that is more oriented to the interpretation of lost architecture (Guidi et al., 2011).

Starting from the reality-based model, two hypothetical previous configurations have been defined, the original one of the fourteenth century (Figure 9-11) and the next one,

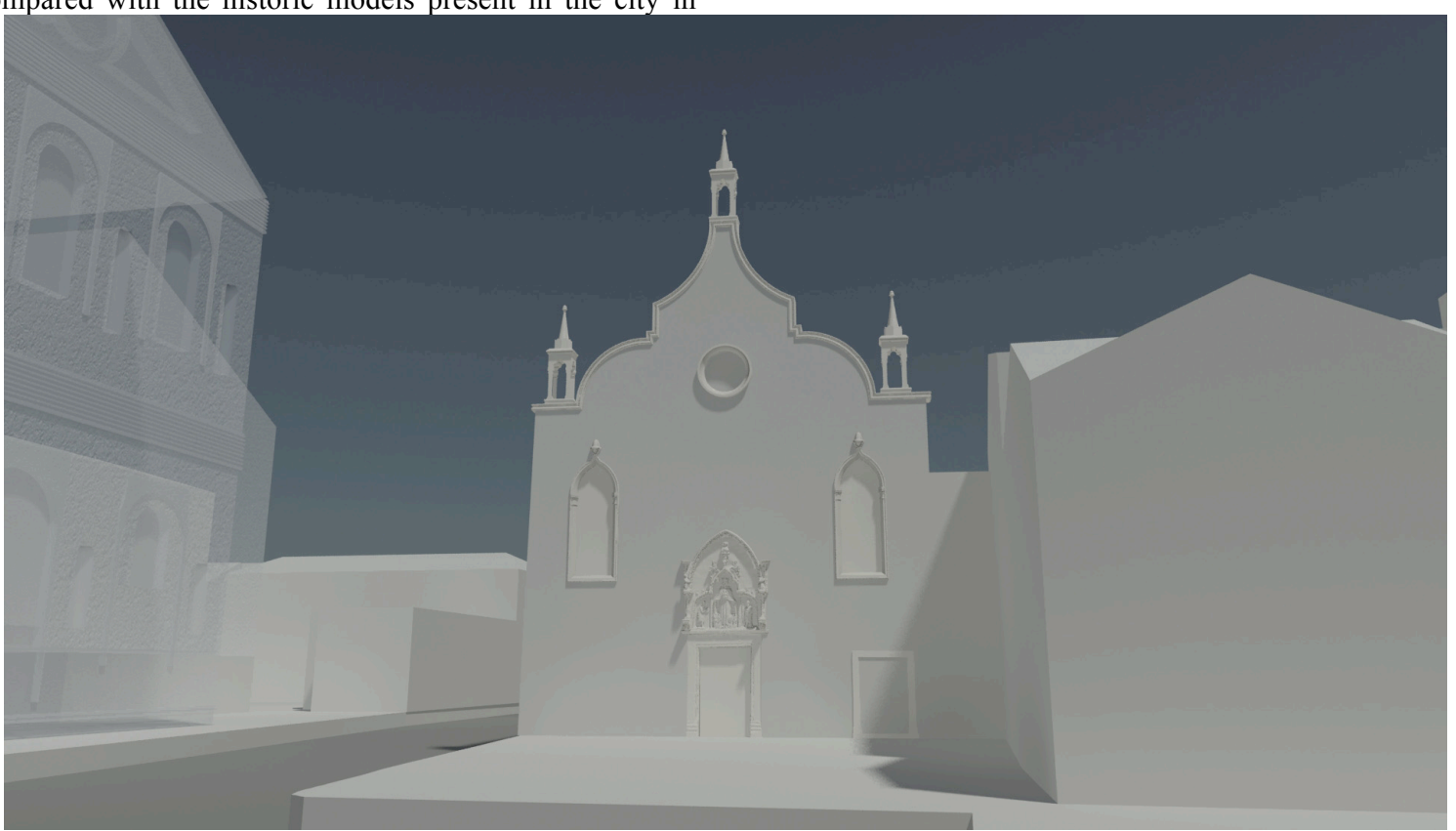

Figure 9: the reconstruction of the original façade dated XIV century 


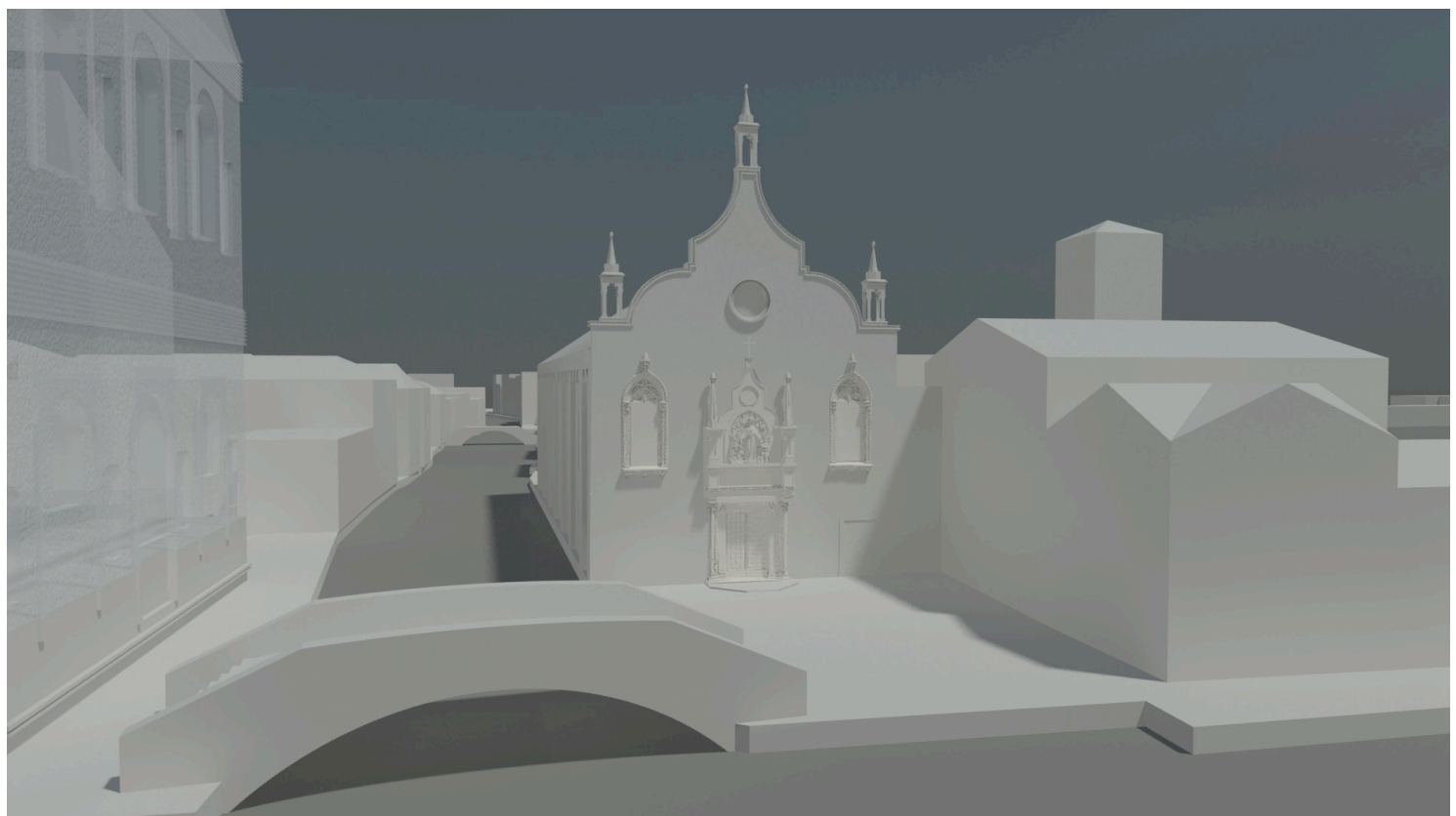

Figure 10: the virtual modelling of the second façade appearance from the XVth to the XVIIth century

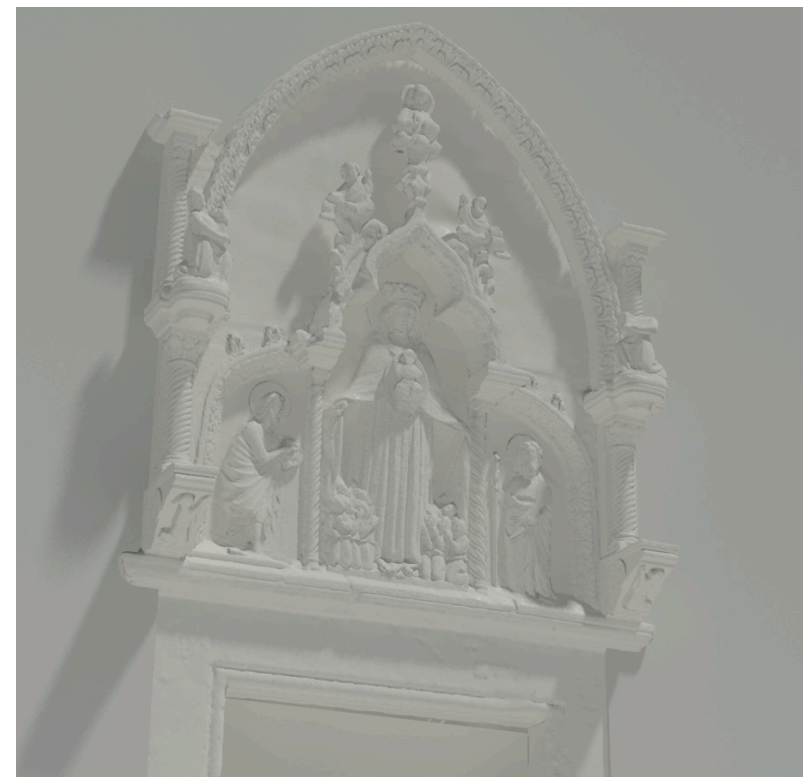

Figure 11: detail of the first stonework of the XIV century

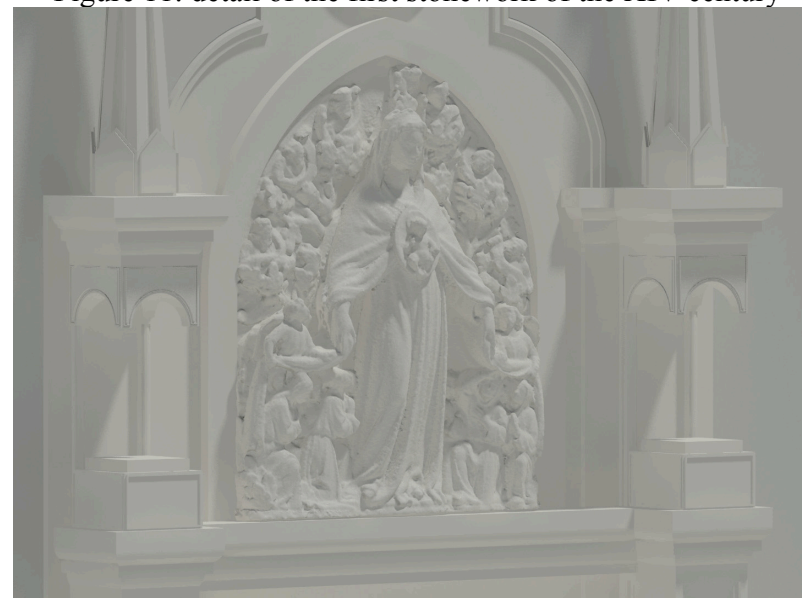

Figure 12: detail of the bas-relief over the entrance from the XVth to the XVIIth century corresponding to the period going from the fifteenth to the seventeenth century (Figure 10-12).

Considering the collected data and their interpretation, the two different portals were merged on their respective modelled facades, then the upper part of the front -higher than the currentand the windows were changed, on the basis of stylistic considerations relating to those that are still visible on the side of factory.

\section{Conclusions}

The paper presented the 3D surveying and modelling of an historical building, with its obvious losses and transformations . The main goal of this work is to show how geomatic tools (Laser scanning and digital photogrammetry), integrated with all the historical and physical analyses and computer vision, can provide the applications that are needed to integrate all of the information on the Misericordia coming from various, often non-intercommunicating sources into a coherent whole. They are tightly interwoven processes to which new technologies can provide an across the board contribution: : the diachronic process of $3 \mathrm{D}$ modelling to reconstruct lost or partially missing monuments must be through the integration and interpretation of historical and real data.

The 3D acquisition and modelling techniques represent an achievable aid for the preservation of cultural heritage because they permit to generate the actual digital copy of an object. Moreover the chance to edit digital data allows not only to describe and explore, but also to compare information, greatly increasing the knowledge and enhancement of a monument.

This presented case study offers an opportunity to draw some conclusions concerning even the areas of dissemination and use by analysing the major forms of communication.

As well as the development of applications addressed to a common public, to virtually navigate through places that are today lost, the digital representation also allows the analysis, management and conservation by using tools directed to experts.

Interactive multimedia products aimed at promoting knowledge of Cultural Heritage to a wide public (scholars, students, tourists, etc.), made from the collection of images produced (renderings, historical maps, texts, reproductions of iconography) starting from the reality based survey and 
structured in an interactive presentation for a diachronic visualization.

Combining and comparing data from different sources requires greater integration of highly varied professional skills and the areas of scholarship to which they belong. Inter- and crossdisciplinary research is essential to achieving results and creating products that, through this interaction, can express their cognitive and educational potential.

\section{References}

References from websites:

English Heritage, 2011. 3D Laser Scanning for Heritage. Advice and guidance to users on laser scanning in archaeology and architecture. Available at www.english-heritage.org.uk

PhotoScan Agisoft, http://www.agisoft.ru

\section{References from Journals}

Remondino, F., Rizzi, A., 2010. Reality-based 3d documentation of natural and cultural heritage sites techniques, problems and examples, Applied Geomatics, Vol.2(3), pp. 85-100.

Brunetaud, X., De Luca, L., Janvier-Badosa, S., Beck, K., AlMukhtar, M., 2012. Application of digital techniques in monument preservation, European Journal of Environmental and Civil Engineering, 16 (5), pp. 543-556.

Guidi G., Beraldin J.A., Atzeni C., 2004, High accuracy $3 d$ modeling of cultural heritage: the digitizing of Donatello. IEEE Trans Image Process 13(3), pp.370-380.

Cignoni P., Scopigno R ., 2008. Sampled 3d models for $\mathrm{CH}$ applications: a viable and enabling new medium or just a technological exercise. ACM Journal on Computing and Cultural Heritage 1(1), Article 2.

Giannattasio, C., Grillo, S. M., and Vacca, G., Interdisciplinary studi for the knoledge and dating of the San Francesco convent in Stampace, Cagliari - Italy (XIII-XXI century). ISPRS Ann. Photogramm. Remote Sens. Spatial Inf. Sci., II-5/W1, pp.139144.

Remondino, F., El-Hakim, S.F., 2006. Image-based 3D modelling: a review. The Photogrammetric Record, 21, pp. 269-291.

A. Koutsoudis, et al., 2013, Multi-image $3 D$ reconstruction data evaluation. Journal of Cultural Heritage, Volume 15, Issue 1, January-February 2014, pp. 73-79.

Westoby M.J., Brasington J., Glasser N.F., Hambrey M.J., Reynolds J.M., 2012. 'Structure-from-Motion' photogrammetry: A low-cost, effective tool for geoscience applications. Geomorphology, Volume 179, pp. 300-314.

Lo Brutto, M. L., Meli, P., 2012. Computer vision tools for $3 D$ modelling in archaeology. International Journal of Heritage in the Digital Era, 1, pp. 1-6.

\section{References from Books:}

Sansovino F., 1581. Venezia città nobilissima et singolare, Venezia.

Stanco F., Battiato S., Gallo G., 2011. Digital Imaging for Cultural Heritage Preservation: Analysis, Restoration, and Reconstruction of Ancient Artworks. CRC Press.

\section{References from Other Literature}

Guidi G., Russo M., 2011. Diachronic 3D reconstruction for lost cultural Heritage. Int. Arch. Photogramm. Remote Sens. Spatial Inf. Sci., XXXVIII-5/W16, pp. 371-376.

Balletti, C., Berto, M., Gottardi, C., Guerra, F., (2013). Ancient structures and new technologies: survey and digital representation of the wooden dome of SS. Giovanni e Paolo in Venice, ISPRS Ann. Photogramm. Remote Sens. Spatial Inf. Sci., II-5/W1, pp. 25-30.

Murphy, M., McGovern, E., and Pavia S., 2011. Historic building information modelling - adding inytelligence to laser and image based surveys, Int. Arch. Photogramm. Remote Sens. Spatial Inf. Sci., XXXVIII-5/W16, pp.1-7.

Paoletti di Osvaldo P., 1893. L'architettura e la scultura del rinascimento. In: Venezia- ricerche storico artistiche, OnganiaNaya, Venezia .

Wolters W., 1976. Venezia Corte Nova dietro alla Scuola Vecchia della Misericordia. In: Il trionfo della cultura gotica. La scultura figurativa veneziana: 1300-1450, Istituto di Scienze Lettere ed Arti, Venezia, pp. 197.

Wolters W., 1996. Ipotesi su Bartolomeo Buon architetto. In: L'architettura gotica veneziana, Istituto di Scienze Lettere ed Arti, Venezia, pp. 273-279.

Nepi Scirè G., 1978. La Scuola Vecchia della Misericordia. In: Quaderni della Soprintendenza ai Beni Artistici e Storici di Venezia, Venezia, n.7. 